THE SPECIAL THEORY OF RELATIVITY 
A Title in the Nature-Macmillan Physics Series 


\title{
THE SPECIAL THEORY OF RELATIVITY
}

\author{
H. Muirhead
}

University of Liverpool

Macmillan Education 
Softcover reprint of the harcover 1st edition 1973 978-0-333-12844-2

All rights reserved. No part of this publication may be reproduced or transmitted, in any form or by any means, without permission.

$$
\begin{array}{r}
\text { First published } 1973 \text { by } \\
\text { THE MACMILLA N PRES LTD } \\
\text { London and Basingstoke } \\
\text { Associated companies in New York Dublin } \\
\text { Melbourne Johannesburg and Madras }
\end{array}
$$

ISBN 978-0-333-12845-9 ISBN 978-1-349-86187-3 (eBook)

DOI 10.1007/978-1-349-86187-3 


\section{Preface}

It has always been a source of surprise to me that no undergraduate textbooks on special relativity have been written by high-energy nuclear physicists. They are the people who most commonly use relativity, and at the same time their approach has more in common with Einstein's original work than most textbooks now show. The latter place too much emphasis (in the opinion of the present author) on what one might call the 'clocks and rods' aspect and too little on the principle of the invariance of physical laws in different reference frames.

This book is an attempt to redress the balance. I have tried to set out the exploitation of the principle of Lorentz invariance in the way in which it is done in high-energy physics, and in doing so have tried to indicate that the basic concept of the invariance of physical laws is a very general one and goes far beyond the context of relativity. Furthermore the techniques developed by high-energy physicists for the construction of physical equations by invariance arguments are an important extension of the principles of dimensional analysis and deserve to be more widely known than they are at present. 
In writing a textbook on special relativity from the high-energy physicist's point of view, I have also felt the necessity to include material on spin and polarisation in relativistic situations. This is a subject of considerable importance in high-energy physics, and is readily amenable to presentation to undergraduates. Nevertheless, the topic is ignored by most writers on special relativity.

The basic plan of the book is that chapter 1 is concerned with historical matters. Chapter 2 deals with the basic Lorentz transformation, and the concept of the invariance of the interval between two events. This invariance principle, together with the implications of the rotation of space-time axes are examined in chapter 3. Chapter 4 is concerned with four-vectors and tensors, and in particular with the momentum four-vector. The treatment of spin and polarisation is made in chapter 5 , and a further discussion of the invariance principle is made. Chapter 6 is concerned with dynamics, chiefly electrodynamics, and the invariance of the transformation properties of physical equations is exploited to examine the behaviour of the motion and polarisation vector ('spin') of charged particles in electrodynamic fields.

In introducing the Lorentz transformation, I was tempted of ignore the early work and worries of the turn of the century and to treat the subject axiomatically. However, I think it is good for students to know that physics rarely evolves in a neat orderly way and that a successful theory normally emerges only after a number of pathways have been tried and found to be blind alleys. For me one of the most interesting facts which emerged in writing chapter 1 was the realisation that Maxwell obviously had worries about the ether concept, and that they lead to a curiously defensive tone in his presentation of certain parts of his Treatise on Electricity and Magnetism.

Except in chapter 1, I have used MKS units for electromagnetic systems. They appear to me to be particularly inappropriate for a textbook on special relativity as they obscure rather than bring out the role of the velocity of light. However, as they are in general use I have reluctantly stuck to them.

I wish to thank I. G. Muirhead for reading the manuscript, and Drs J. Bailey and E. Picasso for supplying suitable diagrams for figures 6.4 and 6.5 .

H. Muirhead 


\section{Contents}

Acknowledgements

1 Historical notes

1.1 Galileo and Newton

1.2 Revolutions in physics in the nineteenth century 5

1.3 Problems

1.4 The age of Einstein

Problems

2 Einstein and relativity 14

$\begin{array}{ll}2.1 \text { Preamble } & 14\end{array}$

$\begin{array}{ll}2.2 \text { The assumptions } & 15\end{array}$

$\begin{array}{ll}2.3 \text { The implications } & 16\end{array}$

$\begin{array}{ll}2.4 & \text { Intervals } \\ 2.5 & 20\end{array}$

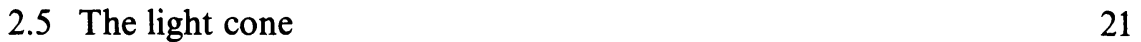

2.6 Invariance properties of the interval 23

$\begin{array}{ll}\text { Problems } & 27\end{array}$ 
3 Applications of the Lorentz transformation 29

3.1 The life span of a meson $\quad 29$

$\begin{array}{ll}3.2 \text { Clocks and rods } & 33\end{array}$

3.3 Time dilatation and Lorentz contraction 34

$\begin{array}{ll}3.4 & \text { Simultaneity and causality } \\ 3.5 & 37\end{array}$

3.5 The clock paradox 39

3.6 The visual appearance of rapidly moving objects 42

3.7 The relativistic transformation of velocities 47

3.8 Successive Lorentz transformations 49

Problems $\quad 50$

4 Four-vectors $\quad 52$

4.1 Introduction $\quad 52$

4.2 The energy-momentum four-vector 54

4.3 Further properties of the momentum four-vector 58

4.4 The Lorentz transformation of the momentum four-vector 60

4.5 Further examples of the Lorentz transformation of four-momenta 64

$\begin{array}{ll}\text { 4.6 The emission of light from moving objects } & 69\end{array}$

$\begin{array}{ll}\text { 4.6.1 The aberration of light } & 70\end{array}$

$\begin{array}{ll}\text { 4.6.2 The Doppler shift } & 72\end{array}$

4.6.3 The intensity of the emitted light $\quad 73$

$\begin{array}{lll}4.7 & \text { The addition of four-vectors } & 75\end{array}$

$\begin{array}{ll}\text { 4.7.1 Compton scattering } & 76\end{array}$

$\begin{array}{ll}\text { 4.7.2 Elastic antiproton-proton scattering } & 78\end{array}$

$\begin{array}{ll}\text { 4.8 The centre of momentum system } & 81\end{array}$

4.9 Other four-vectors, four-tensors 86

Problems

$5 \quad$ Spin and special relativity $\quad 90$

5.1 Angular momentum-a nonrelativistic concept? 90

$\begin{array}{ll}\text { 5.2 The Pauli-Lubanski vector } & 91\end{array}$

5.2.1 Angular momentum in classical mechanics 92

$\begin{array}{ll}\text { 5.2.2 Spin } & 93\end{array}$

5.2.3 The Pauli-Lubanski vector $\quad 94$

$\begin{array}{lll}5.3 & \text { The nonrelativistic limit } & 95\end{array}$

$\begin{array}{lll}5.4 & \text { The Lorentz boost } & 97\end{array}$

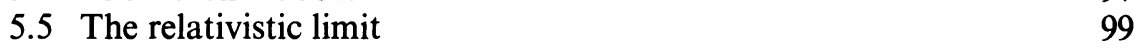

$\begin{array}{ll}5.6 \text { Symmetries in physics } & 100\end{array}$

$\begin{array}{ll}\text { 5.6.1 Symmetries and the interval } & 100\end{array}$

5.6.2 The violation of the conservation laws 101

$\begin{array}{lr}\text { Problems } & 103\end{array}$

6 The Lorentz invariance of physical theories 106

6.1 Maxwell's equations and the conservation of charge 106

6.1.1 The equation of continuity 106

6.1.2 Charge conservation in Lorentz transformations 109

6.2 Maxwell's equations and the Lorentz transformation 111 
6.2.1 Reformulation of the equations 111

6.2.2 The Lorentz transformation of Maxwell's equations 113

6.2.3 The transformation of the fields $\mathbf{B}$ and $\mathbf{E} \quad 118$

$\begin{array}{ll}6.3 \text { Solutions of Maxwell's equations } & 120\end{array}$

6.3.1 The effects of Galilean and Lorentz transformations upon the propagation of electromagnetic waves $\quad 120$

$\begin{array}{lr}\text { 6.3.2 Relativistic wave equations } & 122\end{array}$

$\begin{array}{ll}\text { 6.3.3 Solutions in the Coulomb gauge } & 125\end{array}$

$\begin{array}{ll}\text { 6.3.4 The 'spin' of a photon } & 127\end{array}$

6.4 Invariants of the electromagnetic system 131

6.5 The Lorentz force 131

$\begin{array}{ll}\text { 6.5.1 Derivation } & 131\end{array}$

6.5.2 The magnetic deflection of charged particles 135

6.6 The precession of the polarisation of particles moving in a
homogeneous electromagnetic field

6.6.1 Construction of the equation of motion 137

6.6.2 Solutions for the equation of motion 140

6.6.3 The ' $g-2$ ' experiment 143

$\begin{array}{lr}\text { Problems } & 147\end{array}$

$\begin{array}{lr}\text { Appendixes } & 149\end{array}$

A.1 The Michelson-Morley experiment 149

$\begin{array}{lr}\text { A.2 Vector notation } & 152\end{array}$

A.2.1 The multiplication of vectors $\quad 152$

A.2.2 The differentiation of vectors 154

A.2.3 Successive applications of $\nabla \quad 155$

A.3 Spherical triangles and the Lorentz transformation 155

$\begin{array}{lr}\text { Solutions to problems } & 158\end{array}$

$\begin{array}{ll}\text { Index } & 161\end{array}$ 


\section{Acknowledgements}

The author and publishers acknowledge with gratitude their indebtedness to the following sources for permission to use copuright material.

The Institution of Electrical Engineers for Abstract 2277 from Physics Abstracts, 1905.

page

G. D. Scott and M. R. Viner for their diagram of a plane grid moving at relativistic speeds, from the American Journal of Physics, 334, 534, 1964.

R. S. Shankland for figure 7 from Atomic and Nuclear Physics, Macmillan and Company Limited, 1961.

The Royal Society for the table of Bradley's observations of $\gamma$-Draconis, from the Philosophical Transactions of the Royal Society, 35, $637,1728$.

A. H. Compton and the American Physical Society for the graph showing the wavelength of scattered radiation as a function of the scattering angle, from the Physical Review, 21, 483, 1923. 